\title{
A study of association between thyroid dysfunction and serum anti- mullerian hormone levels in women presenting with infertility
}

\author{
Haripriya Vedantham ${ }^{1}$, Prathyusha Tanuku², \\ Nandini Joshi Nee Jahagirdar ${ }^{3 *}$, Vasundhara Kamineni ${ }^{1}$
}

\begin{abstract}
${ }^{1}$ Department of Obstetrics and Gynaecology, Kamineni Academy of Medical Sciences and Research Center, Hyderabad, India

${ }^{2}$ Department of Obstetrics and Gynaecology, Mallareddy Medical College for Women, Hyderabad, Andhra Pradesh, India

${ }^{3}$ Department of Obstetrics and Gynaecology, Saint Mary’s at Wythenshawe Maternity Hospital, Manchester, United Kingdom
\end{abstract}

Received: 16 August 2020

Accepted: 04 September 2020

*Correspondence:

Dr. Nandini Joshi Nee Jahagirdar,

E-mail: jahagirdar.nandini@gmail.com

Copyright: (C) the author(s), publisher and licensee Medip Academy. This is an open-access article distributed under

\section{ABSTRACT}

Background: This study was conducted to study the association between thyroid dysfunction and serum AMH levels in women presenting with infertility.

Methods: An institution based cross-sectional study including, was conducted at Kamineni hospital fertility clinic among 70 women presenting with infertility during a two year period from May 2016 to April 2018 after fulfilling inclusion criteria.

Results: Hypothyroidism was the most common thyroid dysfunction observed in the study participants and subclinical hypothyroidism was seen predominantly. Age of the women did not seem to influence the prevalence of thyroid disease. Low serum AMH indicating poor ovarian reserve was observed in $70 \%$ of women over $34 \mathrm{yrs}$ suggesting a significant correlation. All the women diagnosed with overt hypothyroidism had low serum AMH levels and half of the women with subclinical hypothyroidism also had low serum AMH levels suggesting a close association between thyroid dysfunction and ovarian reserve. Women with hyperthyroidism had normal AMH levels. Conclusions: Serum AMH levels in infertile patients, were inversely correlated with TSH levels.

Keywords: Anti-Mullerian hormone, Infertility, Ovarian reserve, Thyroid dysfunction

\section{INTRODUCTION}

Infertility affects about $8-12 \%$ of couples worldwide. ${ }^{1,2}$ In India the prevalence is around $3.9-16.8 \% .^{3}$ Thyroid dysfunction and autoimmune thyroiditis are known risk factors for anovulation, menstrual irregularities, subfertility, polycystic ovarian disease (PCOD) and recurrent miscarriages, suggesting a possible effect on the female reproductive axis. ${ }^{4,5}$

The prevalence of subclinical hypothyroidism among women is around $11 \%$ and it increases with age. The prevalence of subclinical and overt hyperthyroidism in India is $1.6 \%$ and $1.3 \%$ respectively. ${ }^{6}$
Determination of ovarian reserve is important in the assessment and treatment of infertility. Among the tests for ovarian reserve, estimation of basal serum FSH, antimullerian hormone (AMH) and antral follicular count (AFC) by sonography were found to be reliable. Unlike basal FSH, AMH levels are gonadotropin independent and exhibit little variation within and between cycles. ${ }^{7,8}$ Hence AMH is considered to be a suitable biomarker of ovarian reserve. ${ }^{9,10}$

Anti-Mullerian hormone (AMH), a dimeric glycoprotein belonging to the transforming growth factor-beta (TGFB) is produced by the granulosa cells of preantral and small antral follicles. ${ }^{11}$ The number of small antral 
follicles, correlate with the size of the residual follicular pool.

Although AMH functions primarily as an autocrine and paracrine regulator of follicular development, it appears in measurable amounts in the serum, therefore chosen as an indicator of ovarian reserve in the present study. ${ }^{12}$

Average TSH levels in infertile women were reportedly higher than those in normal fertile women. ${ }^{13,14}$ Expectedly, ovarian reserve and thereby ovarian function may be affected by impaired thyroid function, although this association has not been elucidated. While some studies have shown association between thyroid dysfunction and diminished ovarian reserve, few studies concluded no significant correlation.

The present study was undertaken to determine the prevalence of thyroid dysfunction and the relationship between thyroid function and ovarian reserve among women presenting with infertility at our urban center.

\section{METHODS}

The aim was to study the association between thyroid dysfunction and serum AMH levels in women presenting with infertility.

The study, an institution based cross-sectional study, was conducted at Kamineni hospital fertility clinic among women presenting with infertility during a two year period from May 2016 to April 2018. Among them, 70 women who fulfilled the inclusion criteria were enrolled after obtaining an informed consent and institutional ethical clearance.

\section{Inclusion criteria}

Women presenting with primary and secondary infertility and age group of 25-40 years

\section{Exclusion criteria}

Known thyroid dysfunction on medication; PCOD; primary ovarian insufficiency; past ovarian surgery; and smoking.

Following enrolment, demographic data was collected, detailed history taken and physical examination performed according to a preexisting proforma. Blood sample was collected on day 2 of cycle for thyroid function tests $(5 \mathrm{ml}$ fasting venous blood sample for serum TSH, T3, T4), serum AMH levels serum FSH and a transvaginal sonography was performed on (day 2 or 3 ) for antral follicular count.

Lab cut off values were: TSH- 0.34-5.6 mIU/L; T3- 0.87$1.78 \mathrm{ng} / \mathrm{ml}$; T4- 6.09-12.23 $\mu \mathrm{g} / \mathrm{dl}$; Serum AMH- 2.2-6.8 ng/ml; Serum FSH- 3.85-8.78 mIU/ml

\section{Statistical analysis}

Data analysis was done using Statistical package for social sciences (SPSS Version 16) for MS Windows. Categorical variables were summarized with $\mathrm{n}(\%)$, while quantitative variables were summarized by mean \pm SD.

Inferential Statistics: The difference in the two groups was tested for statistical significance using parametric tests such as t-test categorical variables tested by chi square test. $\mathrm{P}$ value less than 0.05 was considered statistically significant.

\section{RESULTS}

Majority of women enrolled for the study were in the age group of 25-29 years and the mean age was $29 \pm 3.4$ years.

Table 1: Age wise distribution of the study participants.

\begin{tabular}{|lll|}
\hline Age (years) & Frequency (n) & Percentage (\%) \\
\hline $\mathbf{2 5 - 2 9}$ & 46 & 65.7 \\
\hline $\mathbf{3 0 - 3 4}$ & 17 & 24.3 \\
\hline $\mathbf{3 5 - 4 0}$ & 7 & 10.0 \\
\hline Total & 70 & 100.0 \\
\hline
\end{tabular}

Women with primary infertility constituted $67 \%(\mathrm{n}=47)$ and those with secondary infertility constituted $33 \%$ $(n=23)$.

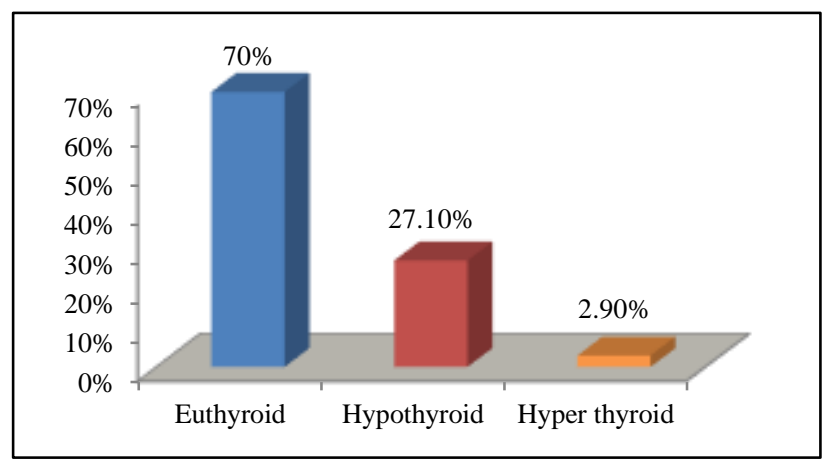

Figure 1: Prevalence of thyroid dysfunction.

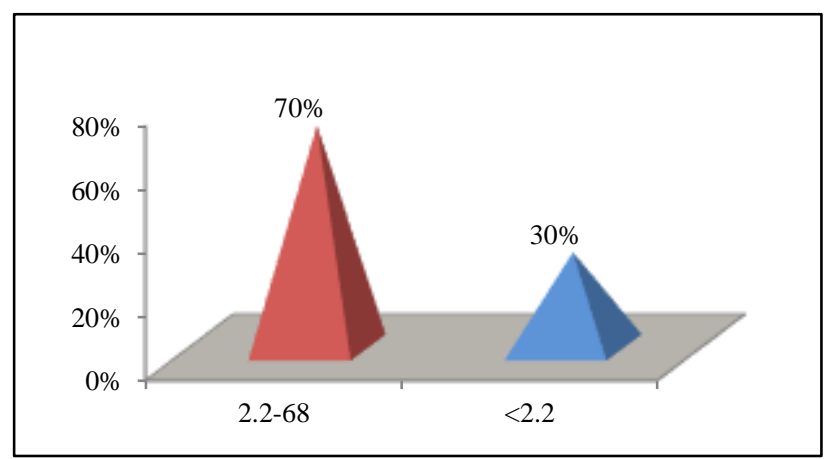

Figure 2: Proportion of infertile women with low serum AMH. 
Thyroid dysfunction was observed in 30\% of women. Hyperthyroidism constituted of $2.9 \% \quad(n=2)$ while hypothyroidism constituted of $27.1 \% \quad(n=19)$, out of which women with subclinical hypothyroidism were $20 \%$ $(n=14)$ and with overt hypothyroidism were around $7 \%$ $(\mathrm{n}=5)$ (Figure 1).

Low serum AMH levels $(<2.2 \mathrm{ng} / \mathrm{ml})$ were noted in $30 \%$ (Figure 2).

Table 2: Percentage distribution of AMH in the study group.

\begin{tabular}{|c|c|c|}
\hline Serum AMH level & $\begin{array}{l}\text { Frequency } \\
\text { (n) }\end{array}$ & Percentage \\
\hline $\begin{array}{l}\leq 0.29 \mathrm{ng} / \mathrm{ml} \text { (undetectable/ } \\
\text { very low range) }\end{array}$ & 3 & $4.3 \%$ \\
\hline $0.30-2.19$ ng/ml (low range) & 18 & $25.7 \%$ \\
\hline $\begin{array}{l}2.2-3.99 \mathrm{ng} / \mathrm{ml} \\
\text { (satisfactory) }\end{array}$ & 47 & $67.1 \%$ \\
\hline 4-6.8 ng/ml (optimal) & 2 & $2.9 \%$ \\
\hline Total & 70 & $100.0 \%$ \\
\hline
\end{tabular}

Table 3: Correlation between age and serum AMH. AGE1 $\times$ AMH cross tabulation.

\begin{tabular}{|lllll|}
\hline \multirow{2}{*}{ AGE1 } & & AMH & & Total \\
& & $2.2-68$ & $<2.2$ & \\
\cline { 2 - 5 } & $<34$ & 48 & 15 & 63 \\
\cline { 3 - 5 } & years & $76.2 \%$ & $23.8 \%$ & $90.0 \%$ \\
\cline { 2 - 5 } & $>34$ & 1 & 6 & 7 \\
\hline \multirow{2}{*}{ Total } & years & $14.3 \%$ & $85.7 \%$ & $10.0 \%$ \\
\hline & & 49 & 21 & 70 \\
\hline
\end{tabular}

Chi square $=11.497 ; \mathrm{df}=1 ; \mathrm{p}$ value $=0.002$

Around $86 \%$ women with low serum AMH level were in the age group $>34$ years and there was significant correlation between low serum AMH and age $>34$ years $(\mathrm{p}=0.002)$.

Table 4: Thyroid dysfunction $\times$ age cross tabulation.

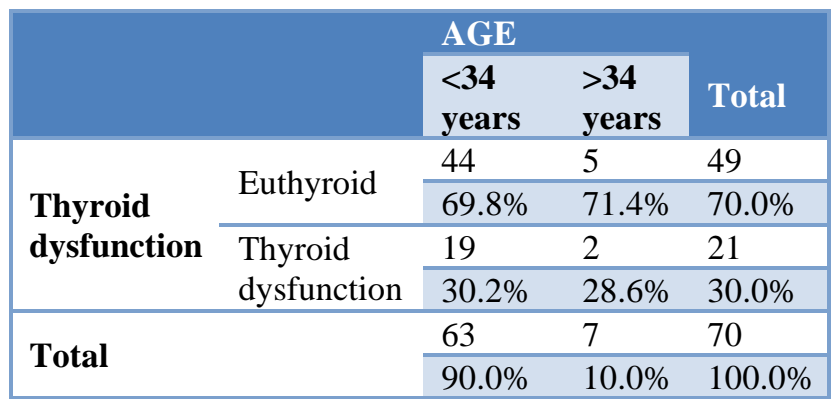

Chi square $=0.008 ; \mathrm{df}=1 ; \mathrm{p}$ value $=0.931$

As shown in Table 5, the proportion of euthyroid women with normal AMH levels constituted $81.6 \%$ compared to $18.4 \%$ of them with low AMH. Among women with thyroid dysfunction, normal and low serum AMH levels were observed in $42.9 \%$ and $57.1 \%$ respectively suggesting a significant relation between thyroid dysfunction and low serum AMH levels $(p=0.001)$.

Table 5. Correlation between thyroid dysfunction with serum AMH levels.

\begin{tabular}{|lllll|}
\hline & & \multicolumn{3}{l}{ AMH } \\
& & Normal & Low & Total \\
\hline \multirow{3}{*}{$\begin{array}{l}\text { Thyroid } \\
\text { dysfunction }\end{array}$} & Euthyroid & 40 & 9 & 49 \\
\cline { 3 - 5 } & & $81.6 \%$ & $18.4 \%$ & $70.0 \%$ \\
\cline { 2 - 5 } & $\begin{array}{l}\text { Thyroid } \\
\text { dysfunction }\end{array}$ & 9 & 12 & 21 \\
\cline { 3 - 5 } Total & & $42.9 \%$ & $57.1 \%$ & $30.0 \%$ \\
\hline \multirow{2}{*}{ Nony } & & $70.0 \%$ & $30.0 \%$ & $100.0 \%$ \\
\hline
\end{tabular}

Chi square $=10.525 \mathrm{df}=1, \mathrm{p}$ value $=0.001$.

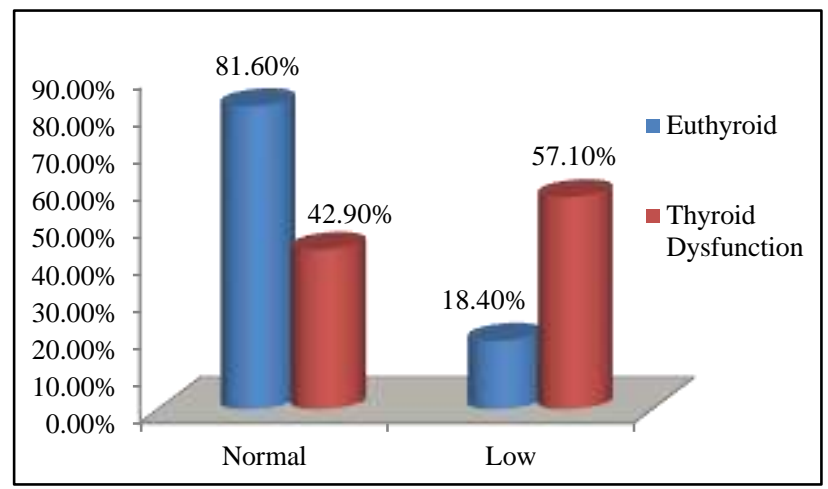

Figure 3: Diagrammatic representation of AMH levels with respect to thyroid status.

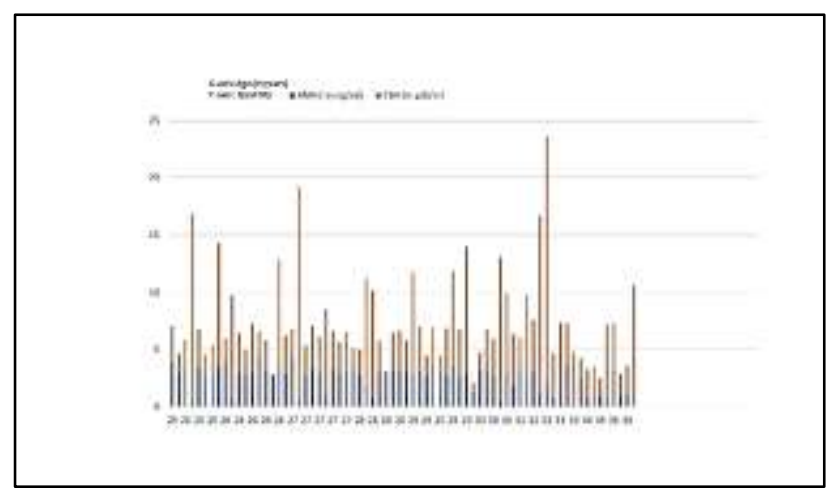

FIGURE 4: Graphical depiction of TSH and AMH of individual study participants by age.

Inverse correlation was observed between serum TSH and AMH levels (Figure 4).

\section{DISCUSSION}

Hypothyroidism is the most common endocrine disorder in women of reproductive age and may affect fertility. While some studies have shown association between thyroid dysfunction and diminished ovarian reserve, few studies have concluded no significant correlation. 
Hypothyroidism was the most common thyroid dysfunction observed in our study (27\% versus $3 \%$ ) and subclinical hypothyroidism was the most common subtype seen in $20 \%$ of them. The study conducted by Unnikrishnan et al in 2009 reported a similar distribution of thyroid disorders among women of reproductive age. ${ }^{6}$

Serum AMH chosen as the biomarker for ovarian reserve was observed to be low $(<2.2 \mathrm{ng} / \mathrm{ml})$ in $30 \%$ of women $(n=21)$, among whom a small proportion $(n=3)$ had $\mathrm{AMH}$ in undetectable range (i.e. $\leq 0.29 \mathrm{ng} / \mathrm{ml}$ ). The mean $\mathrm{AMH}$ in the study was $2.44 \mathrm{ng} / \mathrm{ml}$. Similar results were observed in the study conducted by Kuroda et al, where the mean TSH was $2.55 \mathrm{ng} / \mathrm{ml}^{15}$

There was no significant association between the age of women and thyroid dysfunction ( $p$ value $=0.931$ ), whereas significant association was found between the age of women and their AMH levels ( $\mathrm{p}$ value=0.002). Around $70 \%$ of women in the age group $>34$ years had low serum AMH levels suggesting the effect of advancing age on serum AMH levels. Similar observations were noted in the previous studies conducted by Battikhi in 2016 and Kuroda et al in 2013. ${ }^{15,16}$

It was observed in the present study that majority of women with hypothyroidism had low serum AMH level compared to the euthyroid women and this difference was statistically significant $(\mathrm{p}=0.001)$. These results are consistent with the studies conducted by Battikhi et al, Sammour et al, and Kuroda et al. ${ }^{19}$ Data from all these studies had similar observation of inverse correlation between serum AMH and TSH levels in infertile women (without any factors affecting thyroid and ovarian function).

Among the hypothyroid women with low serum AMH level $(n=12), \quad 58.3 \%$ were having subclinical hypothyroidism $(n=7)$ and $41.6 \%$ were having overt hypothyroidism. We have observed that all women with overt hypothyroidism $(n=5)$ had low serum AMH levels which signifies that thyroid dysfunction may be a factor influencing ovarian reserve in infertile patients.

In our study hyperthyroidism did not seem to affect serum AMH levels. However, a larger study need to be conducted to draw conclusions correlating the both.

The study conducted by Battikhi et al to assess the association between thyroid dysfunction and infertile women at different age groups by measuring antiMullerian hormone $(\mathrm{AMH})$ levels in respect of fertile reproductive women. ${ }^{16}$ This study enrolled infertile and fertile women of different age groups. The results of this study showed that serum AMH levels in infertile patients (not in healthy fertile women) were inversely correlated with patient age and TSH levels. The limitation of this study was healthy fertile women of young age group i.e. $<30$ years were taken as control group and the study group included infertile women of $<35$ years to 45 years, with majority in age group between 36-40 years. Independent studies have shown an increase in incidence of thyroid dysfunction and decrease in AMH levels with advancing age (after 40 years of age). ${ }^{10,16}$ Hence observations from this study cannot be applied to our present study as all groups are not equally represented and matching has not been done with regard to age.

In another study conducted by Al-Azzawi et al, negative correlation (correlation coefficient was -0.016) was observed between serum TSH and serum AMH levels. ${ }^{17}$ However, a statistical significance was not observed $(p=0.898)$. This can probably be explained by the differences in inclusion criteria with respect to the type of fertility considered and the age group under study.

To summarise, most women enrolled for the present study had primary infertility. Advancing age ( $>34$ years) was inversely related to serum AMH levels in these women. Elevated serum TSH levels were associated with significantly low serum AMH and this was more evident in the overt hypothyroidism group. Association between hyperthyroidism and AMH could not be determined because of the very small number of women with this condition in the study.

Limitations of the study were small sample size and a single centre study limit the extrapolation of results to general population.

Although the effect of subclinical hypothyroidism on AMH level was assessed, simultaneous testing for autoimmune thyroid disease would have added more information to study findings and probably influenced the results.

\section{CONCLUSION}

Hypothyroidism was the most common thyroid dysfunction observed in the study participants and subclinical hypothyroidism was seen predominantly. Age of the women did not seem to influence the prevalence of thyroid disease. Low serum AMH indicating poor ovarian reserve was observed in $70 \%$ of women over 34 years suggesting a significant correlation. All the women diagnosed with overt hypothyroidism had low serum AMH levels and half of the women with subclinical hypothyroidism also had low serum AMH levels suggesting a close association between thyroid dysfunction and ovarian reserve. Women with hyperthyroidism had normal AMH levels.

From the results of this study it can be concluded that serum AMH levels in infertile patients, were inversely correlated with TSH levels.

\section{Recommendations}

Possibility of poor ovarian reserve in women with hypothyroidism needs consideration and hence estimation 
of other ovarian markers (serum estradiol, serum FSH, AFC) along with AMH may help draw better conclusions.

\section{Funding: No funding sources}

Conflict of interest: None declared

Ethical approval: The study was approved by the Institutional Ethics Committee

\section{REFERENCES}

1. Sciarra J. Infertility, an international health problem: Int J Gynaecol Obstet. 1994;46:155-63.

2. Population Council. Infertility: Looking back, looking forward: a profile of sexual and reproductive health in India. New Delhi: Population Council; 2004:67-72.

3. Infecundity, infertility, and childlessness in developing countries. DHS Comparative Reports No. Calverton, Maryland, USA: ORC Macro and the World Health Organization; 2004. World Health Organization. Available from: https://dhsprogram.com/publications/publication-cr9comparative-reports.cfm.

4. Krassas GE, Papadopoulou F, Tziomalos K, Zeginiadou T, Pontikides N. Hypothyroidism has an adverse effect on human spermatogenesis: A prospective, controlled study. Thyroid. 2008;18:1255-9.

5. Van den Boogaard E, Vissenberg R, Land JA, van Wely M, van der Post JA, Goddijn M, et al. Significance of (sub) clinical thyroid dysfunction and thyroid autoimmunity before conception and in early pregnancy: A systematic review. Hum Reprod Update. 2011;17:605-19.

6. Menon UV, Sundaram KR, Unnikrishnan AG, Jayakumar RV, Nair V, Kumar H. High prevalence of undetected thyroid disorders in an iodine sufficient adult south Indian population. J Indian Med Assoc. 2009;107:72.

7. Fanchin R, Taieb J, Lozano DH, Ducot B, Frydman R, Bouyer J. High reproducibility of serum antiMullerian hormone measurements suggests a multistaged follicular secretion and strengthens its role in the assessment of ovarian follicular status: Hum Reprod. 2005;20:923.

8. Hehenkamp WJ, Looman CW, Themmen AP, de Jong FH, Te Velde ER, Broekmans FJ. AntiMullerian hormone levels in the spontaneous menstrual cycle do not show substantial fluctuation: J Clin Endocrinol Metab. 2006;91:4057.

9. Hansen KR, Hodnett GM, Knowlton N, Craig LB. Correlation of ovarian reserve tests with histologically determined primordial follicle number. Fertility Steril. 2011;95(1):170-5.

10. de Vet A, Laven JS, de Jong FH, Themmen AP, Fauser BC. Anti-mullerian hormone serum levels: a putative marker for ovarian aging: Fertil Steril. 2002;77:357.

11. Weenen C, Laven JS, Von Bergh AR, Cranfield M, Groome NP, et al. Anti-Mullerian hormone expression pattern in the human ovary: potential implications for initial and cyclic follicle recruitment: Mol Hum Reprod. 2004;10:77.

12. Kevenaar ME, Meerasahib MF, Kramer P, van de Lang-Born BM, de Jong FH, et al. Serum antimullerian hormone levels reflect the size of the primordial follicle pool in mice. Endocrinology. 2006; 147:3228.

13. Gerhard I, Becker T, Eggert-Kruse W, Klinga K, Runnebaum B. Thyroid and ovarian function in infertile women. Hum Reprod. 1991;6(3):338-45.

14. Gerhard I, Eggert-Kruse W, Merzoug K, Klinga K, Runnebaum B. Thyrotropin-releasing hormone (TRH) and metoclopramide testing in infertile women. Gynecol Endocrinol. 1991;5(1):15-32.

15. Kuroda K, Uchida T, Nagai S, Ozaki R, Yamaguchi $\mathrm{T}$, Sato Y, et al. Elevated serum thyroid-stimulating hormone is associated with decreased anti-Müllerian hormone in infertile women of reproductive age. J Assist Reprod Genetics. 2015;32(2):243-7.

16. Battikhi MN. Correlation between AMH and TSH in infertile women. EC Gynaecol. 2018:7(1):12-5.

17. Al-Azzawi OD, Al-Hadithy AH, Amen SS. The effect of thyroid dysfunction on anti-mollurian hormone concentration in the infertile women at the fertile age. Int J Sci Nature. 2015;6(1):45-50.

18. Broer SL, Broekmans FJ, Laven JS, Fauser BC. Anti-Müllerian hormone: ovarian reserve testing and its potential clinical implications. Hum Reprod Update. 2014;20(5):688-701.

19. Sammour HM, Abuelghar WM, El-Salam NE, Ahmed HH. TSH and AMH in Infertile Women. Egyptian J Hosp Med. 2017;69(2):1814-22.

20. Weghofer A, Barad DH, Darmon S, Kushnir VA, Gleicher N. What affects functional ovarian reserve, thyroid function or thyroid autoimmunity? Reprod Biol Endocrinol. 2016;14(1):26.

21. Polyzos NP, Sakkas E, Vaiarelli A, Poppe K, Camus M, Tournaye H. Thyroid autoimmunity, hypothyroidism and ovarian reserve: a crosssectional study of 5000 women based on age-specific AMH values. Human Reprod. 2015;30(7):1690-6.

Cite this article as: Vedantam $\mathrm{H}$, Tanuku $\mathrm{P}$, Jahagirdar NJ, Kamineni V. A study of association between thyroid dysfunction and serum antimullerian hormone levels in women presenting with infertility. Int J Reprod Contracept Obstet Gynecol 2020;9:4097-101. 